\title{
Manganese Removal in Groundwater Treatment Using Marble
}

\section{Ainul Afeeqah Athirah ${ }^{1}$, Noor Aida Saad ${ }^{2, *}$, Muhammad Fitri Mohd Akhir ${ }^{2}$, Nor Azazi Zakaria ${ }^{2}$}

${ }^{1}$ School of Materials and Mineral Resources Engineering, Engineering Campus, Universiti Sains Malaysia, 14300 Pulau Pinang, MALAYSIA

${ }^{2}$ River Engineering and Urban Drainage System Research Centre, Engineering Campus, Universiti Sains Malaysia, 14300 Pulau Pinang, MALAYSIA

*Corresponding Author

DOI: https://doi.org/10.30880/ijie.2019.11.01.006

Received 02 June 2018; accepted 17 September 2018; available online 05 May 2019

\begin{abstract}
Manganese is one of difficult elements to remove in groundwater due to its high solubility in both acid and neutral condition. Thus, this study has investigated the groundwater treatment using high purity marble $(>97 \%)$ in removing manganese. Groundwater sample was taken at USM's Engineering Campus, Malaysia and the concentration of manganese is approximately $0.5 \mathrm{ppm}$ exceeding the Malaysia Water Quality Standard at $0.1 \mathrm{ppm}$. Filtration of groundwater using pebble size marble and sand size marble column filter was done with different flowrate. For pebble size marble column filter, the highest percentage removal is $58.15 \%$ where the flowrate is $0.007 \mathrm{~L} / \mathrm{s}$. On the other hand, for sand size marble column filter, the highest percentage removal is $97.26 \%$ where the flowrate is $0.017 \mathrm{~L} / \mathrm{s}$. Sand size marble particle shows an efficient manganese removal in groundwater compared to pebble size particle.
\end{abstract}

Keywords: Manganese removal, groundwater, Marble size, physical filtration, surface area

\section{Introduction}

Groundwater is the world's largest accessible freshwater and an important resource for human daily uses. Groundwater can be used as drinking water supply, irrigation, industrial uses and many other uses. Approximately onethird of the world's population depend on groundwater for drinking purpose [1]. In fact, there are several states that use groundwater as their primary freshwater in Malaysia source such as Kelantan, Perak and Sabah [2]. As for Kelantan, groundwater is being significantly used for fresh water supply and is the largest groundwater operator in Malaysia. Traditionally people in Kelantan have used groundwater resource as the potable use since early civilization, before fully developed into industrial potable use in 1935 [2].

However, the groundwater cannot be readily use without prior treatment. The groundwater can be contaminated with both organic and inorganic materials which result it to be unsafe and unfit for human use. Several trace metals can be found naturally in the groundwater such as manganese and iron. However, industrial activities such as mining, metallurgy, and solid waste disposal can lead to severe groundwater pollution with elevated concentrations of toxic metals including lead, cadmium and chromium [3].

Contamination of groundwater can result in poor drinking water quality, loss of water supply, degraded surface water systems, high clean-up costs, high costs for alternative water supplies, and/or potential health problems. Drinking water contaminated with bacteria and viruses can result in illnesses such as hepatitis, cholera, or giardiasis [4]. 
Manganese is commonly found in groundwater because of the weathering and leaching of manganese-bearing minerals and rocks into the aquifers; concentrations can vary by several orders of magnitude [5].

Manganese is an essential nutrient needed for human body, but in excess it can lead to neurotoxicity; dysfunctional of the nervous system [6]. Health-based guidelines for the maximum level of manganese in drinking water are set at 0.3 $\mathrm{mg} / \mathrm{L}$ by the U.S. Environmental Protection Agency (EPA), $0.4 \mathrm{mg} / \mathrm{L}$ by the World Health Organization (WHO) and $0.1 \mathrm{mg} / \mathrm{L}$ by the Malaysia Water Quality Standard [7]-[9]. Neurobehavioral deficits in human have been shown to correspond with manganese exposure [10]. Despite of the negative effects on human health, manganese is an important substance in the industry. Manganese is primarily used in manufacture of steels, alloys, and as an ingredient in various products; batteries and fireworks [11].

Manganese gives greyish-black color to the water and this will arise many problems such as staining to any surfaces and also induce doubt in consumer towards the water quality. Removal of manganese in water can be done by various physical, chemical and biological processes. Characterization of manganese present (particulate or dissolved) and also other parameters are crucial step in determining suitable treatment process.

Most methods, such as ion exchange, coagulation flocculation, distillation require high capital and operating costs. The coagulation-flocculation generates sludge, which require extra operational cost for sludge disposal. For ion exchange, due to high concentration of iron and manganese, there is a high risk of fouling and rapid clogging. Therefore, ion exchange is not recommended in treating water with high concentration of iron and manganese.

Calcium carbonate has been proven effective in removing metals, turbidity, suspended solids and total coliform from water, where the removal was up to $96 \%$ [12]. Marble chips are studied for its uses in water treatment since it has alkali properties to act as $\mathrm{pH}$ regulator in acidic water just as limestone. Besides, marble has similar chemical properties like limestone. It is common to find limestone used by industry in water treatment process such as acid mine drainage treatment and neutralizing industrial wastewater.

Different kind of limestones such as pure limestones, brecciated limestones and carbonaceous limestone carry different degree of effectiveness in heavy metal removal [13]. Limestone is also applied in an AMD treatment located at Gangneung, Korea since 1999 and it successfully maintain effective long-term treatment where physicochemical process of co-precipitation/adsorption with iron hydroxide in the AMD stream is a main control variable of the process [14]. Hence, limestone has a strong potential in treating heavy metals from water.

The selection of $\mathrm{CaCO}_{3}$ rock type in a treatment is depending on the purpose of the water treatment. As marble, it has high purity of $\mathrm{CaCO}_{3}$ compared to limestone. Marble is a metamorphic rock while limestone is a sedimentary rock type. Limestone contains many impurities metal and heavy metal. After undergoing high pressure and high temperature over millions of years, those metals have been separated from $\mathrm{CaCO}_{3}$ and produce marble. This natural process is called metamorphism.

Marble is harder and denser than limestone. The hardness of limestone on the Mohs scale is 3 while marble is 4. Thus, it is not easy to break up due to abrasion of water during filtration. The damage from the water abrasion makes the hardness of water increase [8]. Therefore, to reduce the damage abrasion from water, a higher hardness of $\mathrm{CaCO}_{3}$ rock is needed such as marble. This will reduce additional of hardness in water.

In the previous study of manganese removal using limestone, they used pebble size of marble to filter the manganese. However, the highest removal of manganese was $0.2 \mathrm{mg} / \mathrm{l}$ and total removal efficiency was 72\% [15], [16]. In this research work, application of high purity marble based on different sizes by comparing marble pebble size and marble sand size is used to study the removal of manganese. The flow rate is also used to find the optimum in removing manganese.

\section{Methodology}

\subsection{Retention Time, Flowrate Rate and Void Volume}

The retention time, flow rate and void of each sample are measured. Retention time is measured by pouring water above the marble filled column and allow water to flow. The retention time is taken when the water flowed out from the outlet.

After that, the flow rate of each column is measured using a $1.0 \mathrm{~L}$ measuring cylinder. Time taken for water to fill up the $1.0 \mathrm{~L}$ measuring cylinder is recorded.

By knowing the volume, dry mass and bulk density of marbles in column, the void volume can be calculated using the following formula:

$$
\begin{gathered}
V_{s}=\frac{M_{s}}{G_{s} \rho_{w}} \\
\rho_{s}=\frac{M_{s}}{V_{s}}=G_{s} \rho_{w}
\end{gathered}
$$




$$
V_{v}=V-V_{s}
$$

where, $\rho$ s is bulk density of the marble in $\mathrm{kg} / \mathrm{m}^{3}, \mathrm{M}_{\mathrm{s}}$ is weight of the marble in $\mathrm{kg}, \mathrm{V}_{\mathrm{s}}$ is volume of the marble in the column in $\mathrm{m}^{3}, \mathrm{G}_{\mathrm{s}}$ is the specific gravity of marble, $\rho \mathrm{w}$ is density of water in $\mathrm{kg} / \mathrm{m}^{3}, \mathrm{~V}_{\mathrm{v}}$ is void volume in $\mathrm{m}^{3}$, and $\mathrm{V}$ is total volume in $\mathrm{m}^{3}$.

\subsection{Porosity}

The calculation of porosity was referred using this formula:

$$
A=\frac{B}{C} \times 100 \%
$$

where, A is porosity, B is volume of voids and $\mathrm{z}$ is volume of media.

\subsection{Boundary Conditions}

Groundwater sample was extracted from a tube well in USM Engineering Campus, Nibong Tebal, Pulau Pinang located at $5^{\circ} 08^{\prime} 50.5^{\prime \prime} \mathrm{N}$ and $100^{\circ} 29^{\prime} 34.7^{\prime \prime} \mathrm{E}$. Groundwater was pumped out to the surface using a submersible pump. The groundwater was expelled for 3-4 hours to eliminate impurities before taking the sample [17]. The extraction of groundwater sample follows the ASTM by removing 3 times of well capacity before taking the sample.

Groundwater sample is taken using pipette into $50 \mathrm{ml}$ centrifuged tube. The sample is preserved using $3 \%$ Nitric acid in order to prevent oxidation. All the samples are then kept in a cooler box in order to preserve the sample before conduction ICP-OES test.

\subsection{Preparation of Marble Media}

In this study, high grade marble was used as filter media for the filtration process of groundwater. The marble sample was obtained from a marble quarry in Ipoh, Perak. The size of marble as received was ranging from $1 \mathrm{~cm}$ to $10 \mathrm{~cm}$. In order to get various sizes consisting of fine, medium and coarse, jaw crusher and cone crusher were used. The filter media required are as followed Wentworth scale grain. Size reduction is required to obtain marble in pebble and sand size for the filter media.

Jaw crusher was used to obtain coarse to medium size (below 20mm) while cone crusher acted as secondary crusher to get medium to fine sizes (below $4 \mathrm{~mm}$ ). Subsequently, the marble was sieved using sieve shaker (Gilson). The sample passed through $20 \mathrm{~mm}, 14 \mathrm{~mm}, 10 \mathrm{~mm}, 6 \mathrm{~mm}, 4 \mathrm{~mm}, 2 \mathrm{~mm}, 1 \mathrm{~mm}, 600 \mu \mathrm{m}$ and $425 \mu \mathrm{m}$, and $300 \mu \mathrm{m}$ mesh size. The process of crushing and sieving were repeated until sufficient amount of sample was obtained for Sieve was used to separate particles according to their sizes.

After crushing, the materials were sieved using different size of mesh ranging from $14 \mathrm{~mm}$ to $0.4 \mathrm{~mm}$. All the sieves were stacked in a sieve shaker. Sample is poured into the top sieve which has the largest mesh size. Each lower sieve in the column has smaller mesh size than the one above. At the base is a pan to collect sample that finer than the most bottom mesh size.

\subsection{XRF}

A portion of the marble was crushed into powder form before undergo X-ray fluorescence (XRF) to determine the chemical composition. In this project, $25 \mathrm{~g}$ of sample sized below 75 microns were sent for XRF to determine its elemental content.

$\mathrm{X}$-Ray Fluorescence spectrometry is an elemental analysis technique which is also non-destructive. XRF works based on the principle that individual atoms emit X-ray photons of a characteristic wavelength or energy after excited by an external energy source. As the energy emitted is characteristic of a transition between specific electron orbitals in a particular element, the resulting fluorescent $\mathrm{x}$-rays can be used to identify and quantify elements that are present in the sample.

On the other side, a portion of the sample is also undergoing Loss of Ignition (LOI) test. LOI was conducted prior the XRF. LOI is a test used in inorganic analytical chemistry, particularly in the analysis of minerals. It consists of strongly heating a sample of the material at a specified temperature, allowing volatile substances to escape, until its mass ceases to change. This may be done in air, or in some other reactive or inert atmosphere.

\subsection{Filter Design}

There are 8 compartments of column tank based on different sizes starting with the coarser size at top followed by finer size as going down. High purity of marble is chosen as filter media. The volume of filter media is 10.4 liter. Filter 
is arranged stair-like using concept of cascade in which the flow is subjected to gravitational force as shown in Fig. 1. Flowrate of filter media was tested for each size.

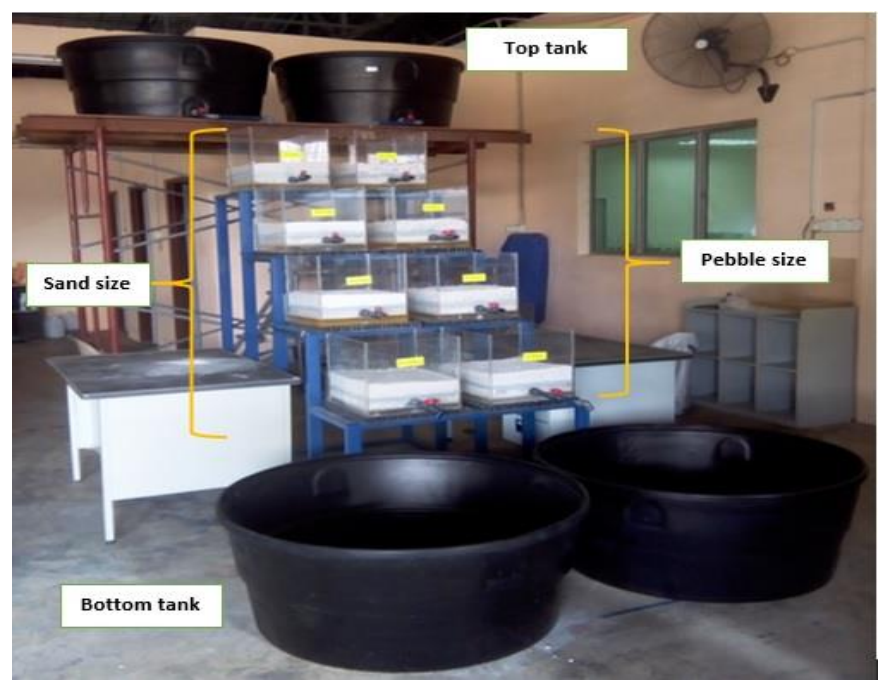

Fig. 1 - Marble column filter arranged according to size from coarser to finer as going down

The first row of four compartments at the right of the Fig. 1 contained marble in pebbles size and consisted of medium $(10 \mathrm{~mm}-14 \mathrm{~mm})$, medium-fine $(6 \mathrm{~mm}-10 \mathrm{~mm})$, fine $(4 \mathrm{~mm}-6 \mathrm{~mm})$ and very fine grain $(2 \mathrm{~mm}-4 \mathrm{~mm})$. Meanwhile, the second row from four compartments at the left of the Fig. 1 contained marble in sand size of very coarse (1mm$2 \mathrm{~mm})$, coarse $(0.6 \mathrm{~mm}-1 \mathrm{~mm})$, coarse-medium $(0.4 \mathrm{~mm}-0.6 \mathrm{~mm})$ and medium grain $(0.3 \mathrm{~mm}-0.4 \mathrm{~mm})$.

Groundwater is stored in the storage tank after collected from tube well and the experiment was carried out in the same day. The collected groundwater is then pumped to the roof tank and flow to the column using gravity. The flowrate is controlled by the valve before entering the column. The flowrate was chosen based on preliminary experiment result to prevent overflow occurs at the most bottom column. Finer size means more retention time and slower flowrate

\subsection{Filtration Process}

The groundwater is filtered from top column to bottom column in sequence of decreasing grain size marbles. The filtration process uses two sets of columns with different size range (pebble size and sand size). 1 set contains 4 filter columns. There are 4 flow rates used to determine optimum flow rate for contaminant removal using the marble column filter.

The flow rates selected are $0.007,0.008,0.011$, and $0.017 \mathrm{Ls}^{-1}$, which is $60 \mathrm{~s}, 90 \mathrm{~s}, 120 \mathrm{~s}$ and $150 \mathrm{~s}$ for per liter of groundwater. The outlet valve of each column is adjusted to control the output flow rate. The input and output water samples of the marble column filter are collected for ICP-OES analysis and also analyzed using handheld multiparameter.

\subsection{ICP-OES Analysis}

Induction coupled plasma (ICP) was used to analyze the groundwater content. ICP-OES is a type of mass spectrometry that is capable of metal and non-metal concentration detection. In this project, marble sample was sent to the lab for ICP-OES testing to detect concentration of manganese in the groundwater sample. Groundwater samples are filtered using 0.45-micron syringe filter to separate particle remain. Afterwards, standard ranges are selected $0.1,0.15$, $0.2,0.75,1.0$ to be calibrated with the samples. Groundwater samples are analyzed for 23 metal elements by inductively coupled plasma-atomic emission spectroscopy (ICP-OES; PerkinElmer Optima 7300 DV). Then calibration graphs are analyzed to find best wavelength that give accurate percentage of element concentration. RHD above $5 \%$ is not acceptable for accurate data.

\section{Results and Discussion}

\subsection{XRF Result for Marble}

XRF was one of the characterizations done on raw marble. XRF analysis was summarized in Table 1 which shows the elemental composition of $\mathrm{CaO}$ alongside its corresponding wt $\%$. 
Table 1 - XRF result for $\mathrm{CaCO}_{3}$ content

\begin{tabular}{cc}
\hline Compound & Weight Percentage (\%) \\
\hline Calcium Oxide, $\mathrm{CaO}$ & 54.588 \\
Magnesium Oxide, $\mathrm{MgO}$ & 1.134 \\
Aluminium Oxide, $\mathrm{Al}_{2} \mathrm{O}_{3}$ & 0.325 \\
Silica, $\mathrm{SiO}_{2}$ & 1.521 \\
Phosphorus pentoxide, & 0.021 \\
$\mathrm{P}_{2} \mathrm{O}_{5}$ & 0.065 \\
Potassium oxide, $\mathrm{K}_{2} \mathrm{O}$ & 0.576 \\
Iron oxide, $\mathrm{Fe}_{2} \mathrm{O}_{3}$ & 0.007 \\
Nickel Oxide, $\mathrm{NiO}_{\text {OrO }}$ & 0.008 \\
Copper Oxide, $\mathrm{CuO}$ & 0.026 \\
Manganese Oxide, $\mathrm{MnO}$ & 0.028 \\
Strontium Oxide, $\mathrm{SrO}$ & 41.701 \\
Loss on Ignition, $\mathrm{LOI}$ & 100 \\
Total & \\
\hline
\end{tabular}

As marble primarily consists of calcium carbonate, it was expected for the $\mathrm{CaO}$ content to be the highest in concentration as shown in Table 1 . The marble composed of $97.3 \% \mathrm{CaCO}_{3}$ which means it is a high-grade marble $\left(\mathrm{CaCO}_{3}\right.$ more than 95\%). The impurities of other elements are in a low percentage which only about $2.7 \%$ of the sample.

\subsection{Pebble Size Marble Column Filter}

Groundwater was treated using pebble size column filters with different flow rates $\left(0.017 \mathrm{Ls}^{-1}, 0.011 \mathrm{Ls}^{-1}, 0.008\right.$ $\mathrm{Ls}^{-1}$ and $0.007 \mathrm{Ls}^{-1}$ ) for each experiment run. To validate the accuracy of data, RSD data showed below than $5 \%$ and this data was accepted.

After filtration, it was expected for the manganese concentration to reduce in the groundwater along with other contaminants such as potassium, magnesium and sodium more than removal in pebble size column filter. Therefore, the best flow rate can be determining by looking at the flow rate which has the highest percentage removal. ICP-OES analysis was done to determine the concentration of elements presence in groundwater after the filtration process. The result was summarized as follow in Table 2.

Table 2 - Percentage of manganese removal via pebble size marble filtration

\begin{tabular}{ccccc}
\hline $\begin{array}{c}\text { Flow rate } \\
(\mathbf{l} / \mathbf{s})\end{array}$ & $\begin{array}{c}\text { Mean Conc. Before } \\
\text { Filtration }(\mathbf{p p m})\end{array}$ & $\begin{array}{c}\text { Mean Conc. After } \\
\text { Filtration }(\mathbf{p p m})\end{array}$ & $\begin{array}{c}\text { Removal Percentage } \\
\mathbf{( \% )}\end{array}$ & $\begin{array}{c}\text { RSD } \\
(\boldsymbol{\%})\end{array}$ \\
\hline 0.007 & 0.509 & 0.213 & 58.15 & 1.34 \\
0.008 & 0.522 & 0.298 & 42.91 & 0.11 \\
0.011 & 0.513 & 0.228 & 55.56 & 2.79 \\
0.017 & 0.495 & 0.288 & 41.82 & 0.81 \\
\hline
\end{tabular}

From the graph, it can be concluded that the highest percentage removal recorded is at $58.15 \%$ with flow rate of $0.007 \mathrm{~L} / \mathrm{s}$. This was probably due to high retention time of groundwater sample during this flowrate. The lower the flowrate the higher the retention time.

In nutshell, for pebble size marble column filter, the highest percentage removal of manganese was $58.15 \%$ while the lowest was $41.82 \%$. Flowrate of $0.007 \mathrm{~L} / \mathrm{s}$ was the most effective flowrate compared to remaining 3 flowrates in terms of percentage of manganese removal. Thus, the best retention time is 1 hour 39 minutes.

\subsection{Sand Size Marble Column Filter}

When comparing to pebble size marble, sand size marble has lower porosity than pebble size marble. This contributes a better filtration and trapping metal elements. Based on Table 3, the highest percentage removal was taken at $96.5 \%$ with flow rate of $0.017 \mathrm{l} / \mathrm{s}$. This was opposed from what was expected. More retention time was expected to give better percentage removal. 
Table 3 - Percentage of manganese removal via sand size marble filtration

\begin{tabular}{ccccc}
\hline $\begin{array}{c}\text { Flow rate } \\
(\mathbf{l} / \mathbf{s})\end{array}$ & $\begin{array}{c}\text { Mean Conc. Before } \\
\text { Filtration }(\mathbf{p p m})\end{array}$ & $\begin{array}{c}\text { Mean Conc. After } \\
\text { Filtration }(\mathbf{p p m})\end{array}$ & $\begin{array}{c}\text { Removal Percentage } \\
(\boldsymbol{\%})\end{array}$ & $\begin{array}{c}\text { RSD } \\
(\boldsymbol{\%})\end{array}$ \\
\hline 0.007 & 0.504 & 0.019 & 91.29 & 1.76 \\
0.008 & 0.505 & 0.044 & 96.23 & 1.04 \\
0.011 & 0.494 & 0.021 & 95.75 & 2.6 \\
0.017 & 0.511 & 0.014 & 97.26 & 0.34 \\
\hline
\end{tabular}

At flowrate 0.007 1/s shown in Fig. 3, the performance of sand size marble has dropped to 91.29\%. This shown the limitation of retention time after 1 hour 39 minutes. In sand size marble column filter, shorter retention time showed the highest removal percentage of manganese.

In nutshell, for sand size marble column filter, the highest percentage removal of manganese was $96.5 \%$ while the lowest was $91.29 \%$. Flowrate of $0.017 \mathrm{~L} / \mathrm{s}$ was the most effective flowrate compared to remaining 3 flowrates in terms of percentage of manganese removal. Therefore, the best retention time is 40 minutes.

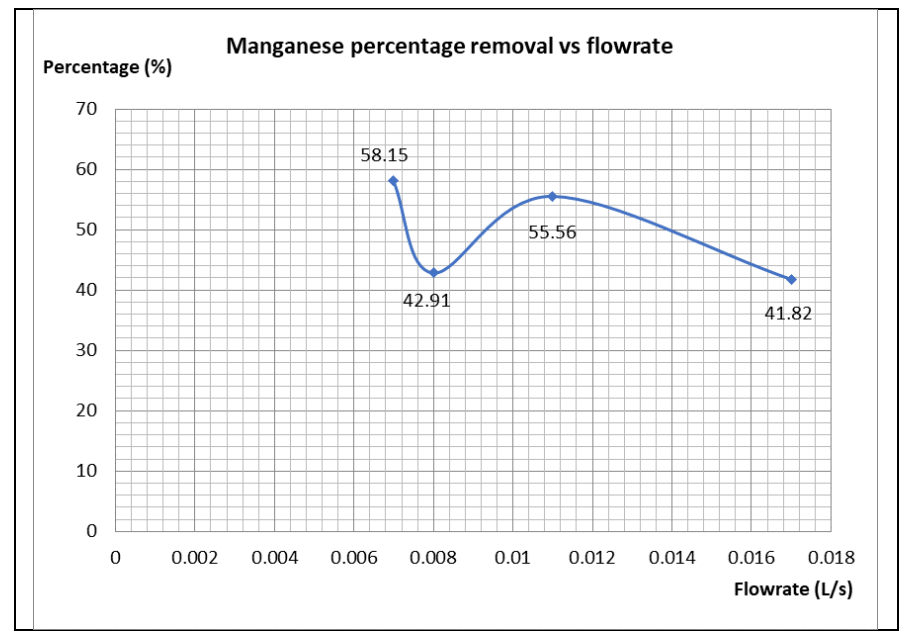

Fig. 2 - Graph manganese percentage removal vs flow rate for pebble size marble filter

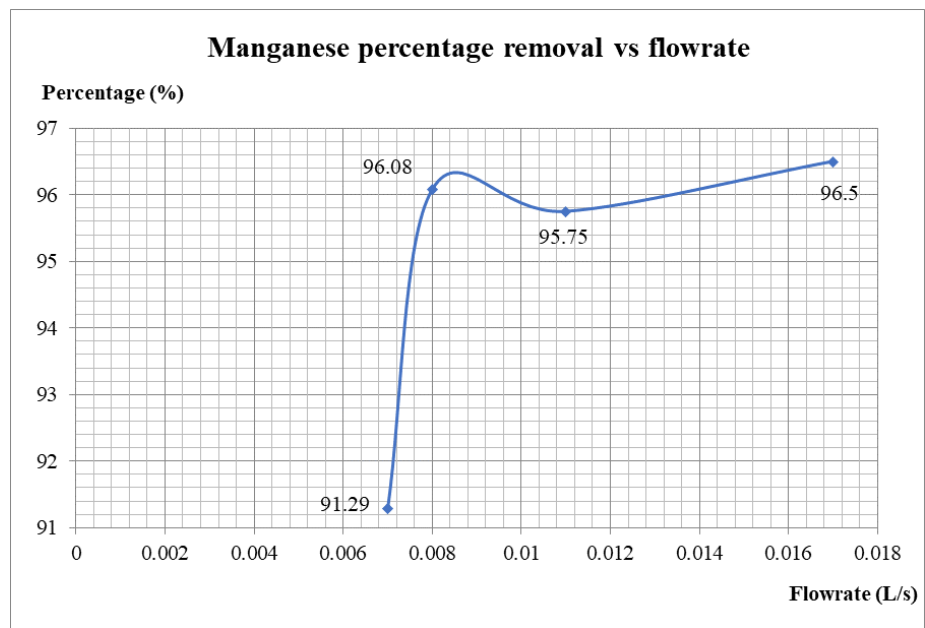

Fig. 3 - Graph manganese percentage removal vs flow rate for sand size marble filter

According to the Table 3 and Table 4, the porosity of marble in pebble size was above $40 \%$ compared to marble in sand size where the porosity was below $30 \%$. When relating the filtration performance of marble in sand size with these data, it indicates low porosity below $30 \%$ can do better filtration in removing manganese. The lower the porosity, the higher removal of manganese. However, too low porosity can cause problems clogging. Below $0.3 \mathrm{~mm}$ of marble size increases the plasticity of the marble and tends to agglomeration and cementation. 
Table 4 - The porosity of marble in pebble size

\begin{tabular}{cccc}
\hline $\begin{array}{c}\text { Particle Size } \\
(\mathbf{m m})\end{array}$ & $\begin{array}{c}\text { Volume of Void } \\
\left(\mathbf{m}^{\mathbf{3}}\right)\end{array}$ & $\begin{array}{c}\text { Volume of Media } \\
\left(\mathbf{m}^{\mathbf{3}}\right)\end{array}$ & $\begin{array}{c}\text { Porosity } \\
(\boldsymbol{\%})\end{array}$ \\
\hline $10-14$ & 0.0047 & 0.0069 & 68.12 \\
$6-10$ & 0.004 & 0.0069 & 57.97 \\
$4-6$ & 0.0034 & 0.0069 & 49.28 \\
$2-4$ & 0.0029 & 0.0069 & 42.03 \\
\hline
\end{tabular}

Table 5 - The porosity of marble in sand size

\begin{tabular}{cccc}
\hline $\begin{array}{c}\text { Particle Size } \\
(\mathbf{m m})\end{array}$ & $\begin{array}{c}\text { Volume of Void } \\
\left(\mathbf{m}^{\mathbf{3}}\right)\end{array}$ & $\begin{array}{c}\text { Volume of Media } \\
\left(\mathbf{m}^{\mathbf{3}}\right)\end{array}$ & $\begin{array}{c}\text { Porosity } \\
(\mathbf{\%})\end{array}$ \\
\hline $1-2$ & 0.0019 & 0.0069 & 27.54 \\
$0.6-1$ & 0.0014 & 0.0069 & 20.29 \\
$0.4-0.6$ & 0.0011 & 0.0069 & 15.94 \\
$0.3-0.4$ & 0.0009 & 0.0069 & 13.04 \\
\hline
\end{tabular}

\section{Summary}

Groundwater treatment was studied and there are many other methods for groundwater treatment, but the most economical and flexible method is by physical filtration treatment. Removal of manganese in groundwater using pebble and sand size marble column filter are measured and the sand size marble filter is more effective compared to pebble size marble column filter. Pebble size marble column filter can remove $58.15 \%$ of manganese in groundwater at flow rate $0.007 \mathrm{l} / \mathrm{s}$ while sand size marble column filter can remove manganese in groundwater up to $96.5 \%$ at flow rate $0.017 \mathrm{l} / \mathrm{s}$. As conclusion, marble in sand size contributes a better filtration and trapping metal elements due to higher retention time and lower porosity compared to marble in pebble size.

\section{References}

[1] Kura, N. U., Ramli, M. F., Sulaiman, W. N. A., Ibrahim, S. and Aris, A. Z. (2018), An verview of groundwater chemistry studies in Malaysia. Enviromental Science of Pollution Research, 25, 7231-7249.

[2] Tawnie, I., Sefie, A., Normi, I. A., Shamsuddin, M. K. N. and Mohamed, A. (2016). Overview of groundwater contamination in Malaysia. The 12th International Symposium on Southeast Asian Water Environment, Hanoi, Vietnam, pp 28-30.

[3] Goher, M. E., Hassan, A. M., Abdel-Moniem, I. A., Fahmy, A. H., Abdo, M. H. and El-sayed, S. M. (2015). Removal of aluminum, iron and manganese ions from industrial wastes using granular activated carbon and Amberlite IR-120H. Egyptian Journal Of Aquatic Research, 41, 155-164.

[4] Environmental Protection Agency (2003). Drinking water advisory: Consumer Acceptability advice and health effects analysis drinking water advisory. Washington, pp 34.

[5] Belvisoa, C., Cavalcantea, F., Di Gennarob, S., Lettinoa, A., Palma, A., Ragonea, P. and Fiorea, S. (2014). Removal of Mn from aqueous solution using fly ash and its hydrothermal synthetic zeolite. Journal of Environmental Management, 137, 16-22.

[6] Hallberg, K. B. and Johnson, D. B. (2005). Biological manganese removal from acid mine drainage in constructed wetlands and prototype bioreactors. Science of Total Environment, 338, 115-124.

[7] United State Environmental Protection Agency (2018). 2018 Edition of the Drinking Water Standards and Health Advisories. Washington, pp 8-10.

[8] Gorchev, H. G. and Ozolins, G. (2011). WHO guidelines for drinking-water quality. WHO Chronical, 38, $104-108$.

[9] Department of Environment Malaysia (2006). Malaysia Environmental Quality Report 2006. Putrajaya, p 43.

[10] Meyer-Baron, M., Schäper, M. and Knapp, G. (2013). NIH public access author manuscript neurotoxicology. The neurobehavioral impact of manganese: Result. Neurotoxicology, 36, 1-23.

[11] Post, J. E. (1999). Manganese oxide minerals: Crystal structures and economic and environmental significance. Proceedings of the National Academy of Sciences of the United States, 96, 3447-3454.

[12] Adlan, M. N., Aziz, H. A. and Maung, H. T. (2008). Performance of horizontal flow roughing filter using limestone media for the removal of turbidity, suspended solids, biochemical oxygen demand and coliform organisms from wastewater. International Journal of Environmental Waste Management, 2, 203-214.

[13] Yao, Z., Zhou, L., Bao, Z., Gao, P. and Sun, X. (2010). High efficiency of heavy metal removal in mine water by limestone. Chinese Journal of Geochemistry, 28, 293-298.

[14] Shim, M. J., Choi, B. Y. and Lee, G. (2015). Water quality changes in acid mine drainage streams in Gangneung, Korea, 10 years after treatment with limestone. Journal of Geochemical Exploration, 159, 234-242. 
[15] Mohd Sanusi, A., Adlan, M. N., Mohd Remy Rozainy, M. A. Z. and Jamil, R. (2016). Removal of iron and manganese using cascade aerator and limestone roughing filter. MATEC Web Conference, 47, pp 05006.

[16] Akbar, N. A., Abdul Aziz, H. and Adlan. M. N. (2015). Iron and manganese removal from groundwater using high quality limestone. Applied Mechanics and Materials, 802, 460-465.

[17] Vail, J. (2013). SESD Operating procedure groundwater sampling. SESDPROC-301-R3. Georgia: United State Environmental Protection Agency, Science and Ecosystem Support Division, pp 13-17. 